\title{
Using gamification to enhance staff motivation in logistics
}

\author{
Jan Hense ${ }^{1}$, Markus Klevers ${ }^{2}$, Michael Sailer ${ }^{1}$, Tim Horenburg ${ }^{2}$, Heinz \\ Mandl $^{1}$ and Willibald Günthner ${ }^{2}$ \\ ${ }^{1}$ Ludwig-Maximilians-Universität München, Empirical Education and Educational \\ Psychology, Germany \\ ${ }^{2}$ Technische Universität München, Institute for Materials Handling, Material Flow and \\ Logistics, Germany
}

\section{Staff motivation as a key challenge in logistics}

Logistics is concerned with effectively managing the flow of materials and supplies for production, commerce and other purposes (Christopher, 2003). Transport logistics deals with resource flows on a large scale level, as it involves transport by land, water, and air. A second domain of logistics is intralogistics, which is concerned with the internal handling of materials and supplies within specific production sites or intermediate storage facilities (Arnold, 2006). This paper focuses on intralogistics or, more specifically, on one of its central tasks, order picking.

Despite ongoing automation efforts, order picking still frequently involves intensive and repetitive manual labour. For fulfilling a customer order, workers typically receive lists of items to be picked from storage and combined in a shipment. Orders have to be fulfilled under time constraints with as few errors as possible in shifts which can easily involve dozens of orders. Due to these challenges and context conditions, and taking into account that order picking is typically performed by low-paid unskilled workers, it is not surprising that staff motivation and high turnover rates are recurrent problems for efficiency in intralogistics. However, most optimization approaches in order picking concentrate on technical aspects, leaving out the human factor (cf. Coffey, 1999).

This paper introduces gamification as an innovative approach to enhance staff motivation in intralogistics. Gamification is a recent trend (originally from marketing) that quickly spread to other areas of application such as education and training, traffic control, or influencing environmental behaviour. Conceptually, gamification denotes the application of game elements for engagement, motivation, learning, or problem-solving purposes in non-gaming, real world contexts (cf. Kapp, 2012, p. 10). As games continually succeed in luring players into investing large amounts of time and effort, it is expected that some of the mechanisms making them effective entertainment devices can also be used in nongaming environments. 
This paper presents the theoretical background and concept of "GameLog" (Gamification in intralogistics - Fostering motivation and productivity in order picking), which is aimed at developing a gamification approach for enhancing motivation in intralogistics. We first analyze current approaches to staff motivation in logistics (section 2), afterwards discuss psychological perspectives on fostering motivation in logistics (section 3) and then introduce gamification and analyze its potential for motivation in logistics (section 4). Subsequently, we describe the GameLog project in detail (section 5) and conclude by giving an outlook on its expected outcomes from practical and research perspectives.

\section{Current approaches to staff motivation in logistics}

Workers in conventional intralogistical processes like manual order picking (see Figure 1) or operating fork lifters are faced with the monotonous fulfilment of steady, recurring tasks. This can lead to fatigue and especially a loss of motivation in the long-term (ten Hompel, Sadowsky \& Beck, 2011). This is supported by a case study from 2012 in which the motivation of workers in intralogistics is specified as very low compared to other business tasks (Link, Müller-Dauppert \& Jung, 2012).

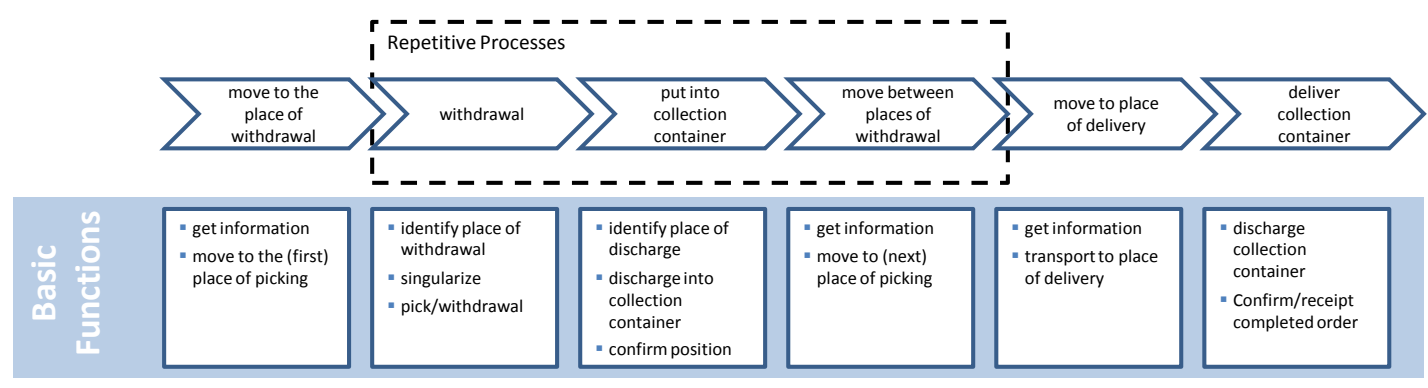

Figure 1: Process Overview of manual order picking

Intrinsic and extrinsic motivation can be distinguished while designing a motivation system for logistic processes (see chapter 3 ). The most important variables (Pfohl, 2004a) within extrinsic motivation salary and working time are primarily the focus of companies' management practices. Those salary-based incentive systems can be divided into performance-related and potential-related salary systems (Wagner, 1995). While potential-related systems take the qualification for the certain work task as a basis, performance-related systems rely on surveyed key performance indicators and their correlation to the salary (Pfohl, 2004a). Thus, performance measurement must lead to methodically accepted and reproducible 
results. Objective measurement is a basic prerequisite for a salary-based incentive system (Pulverich \& Schietinger, 2009). Additionally, a transparent composition of basic salary and bonus is essential for the success of the system (Zaunmüller, 2005).

Most production companies just concentrate on extrinsic monetary incentives to increase motivation, but those incentives are commonly considered short-term instruments (Pfohl, 2004a). In the long-term, motivation-enhancing tools like job rotation, job enlargement, job enrichment and group work (Jünemann \& Schmidt, 2000) are rarely used in intralogistics (Link et al., 2012). Comprehensive intrinsic models are rarely found. The only findings that could be made while reviewing the literature and applying the research for the GameLog project were the creation of communication areas such as coffee corners to improve the corporate atmosphere, the honouring of staff with innovation prices for good ideas and the sensitization for the produced good to emotionalize the worker and create a certain level of enthusiasm (Bundesverband Materialwirtschaft, Einkauf und Logistik, 2008). A comprehensive incentive system directly connected to the working process and the measured performance indicators could not be found while working on this research project, although this could influence the motivation of staff in intralogistics more than a simple extrinsic system (Link, Müller-Dauppert \& Jung, 2012; Pfohl, 2004b).

\section{Psychological perspectives on fostering motivation in logistics}

As current approaches to fostering staff motivation in logistics seem deficient, we used an explicitly psychological perspective in grounding our gamification approach described below. Generally speaking, motivation refers to those psychological processes that are responsible for initiating and continuing goal directed behaviors (Schunk, Pintrich \& Meece, 2007).

Within our context, the two variants learning motivation and work motivation are relevant. While conceptually different, both are closely related to each other. Learning motivation is important when instructing new staff, while work motivation is crucial for their ongoing order-picking activities. The role of motivation in these processes can be summarized by the simplifying formula "(ability + skills) $\mathrm{X}$ motivation". This expresses that motivation is an essential component for realizing a person's potential abilities and skills in a given situation.

An important distinction in motivation research concerns intrinsic and extrinsic motivation (Ryan \& Deci, 2000). While extrinsic motivation relies on incentives or expected consequences of an action, intrinsic motivation stems from fulfilling the action itself. Here, contents and execution of an action are so attractive that no further external motivational sources are needed. Empirically, it could be shown that intrinsic motivation is positively associated with learning and work outcomes, while extrinsic motivators do not necessarily result in better performance. In fact, 
existing intrinsic motivation can be corrupted by additionally providing external motivators. As the manual and repetitive tasks encountered in intralogistics offer relatively little opportunity for intrinsic motivation, we expect that gamification can provide additional options for making order picking more attractive.

In motivation research, five principal perspectives can be differentiated. These do not necessarily contradict each other but can become relevant in varying degrees in different contexts (Krapp, 1993). They can also be used to analyze possible motivational effects of different gamification elements (cf. Section 4).

1. The trait perspective investigates individual characteristics as sources of motivation, which are relatively stable over time and contexts. Corresponding research tries to identify general classes of motives, needs and characteristics, such as achievement motive, need for recognition, sensation seeking, or need for affiliation.

2. In the behaviourist learning perspective, motivation is interpreted as the result of previous experiences. Therefore, past positive and negative reinforcements influence the probability of a specific behaviour in the future. Examples are providing monetary incentives, or positive and negative feedback.

3. The cognitive perspective understands motivation as a rational deliberation of ends and means, and emphasizes the role of internal processes such as expectancies, estimation, and assessment. Accordingly, motivation is dependent upon situation-specific goals, expectancies regarding the consequences of one's actions and the subjective value of these consequences.

4. Self determination theory provides a further perspective in motivation research. It focuses on the three universal psychological needs for competence, autonomy, and social relatedness. According to this perspective, people will be motivated to work and learn if they encounter feelings of being competent in dealing with a situation or task, it they are free to make their own choices, and if they are part of a community with relevant others.

5. Contrary to the previous approaches, the perspective of interest emphasizes individual preferences and content aspects. It is expected that motivation results from the specific relation of a person to the contents or subject matter of a task. Ideally, this can lead to feelings of flow, i.e. of being fully immersed in an activity.

Given the above analysis of current approaches to staff motivation in logistics, it is evident that the predominant approach is behaviourist. Most often we find incentive systems based on performance measures and predefined time standards, which are subject to dynamic adaption to normal performance. As elaborated in the following section, we expect that our gamification approach will open additional opportunities for increased motivational leverage in intralogistics. 


\section{Gamification as an innovative approach to enhance motivation}

Because of the broad spectrum of gamification variations, there is no universal definition of the term. Deterding, Dixon, Khaled \& Nacke (2011) propose a working definition for gamification as "the use of game design elements in non-game contexts" ( Deterding et al., 2011, p. 2). The simplicity of this definition bears a potential risk of trivializing the gamification phenomenon. It is more than adding game elements like points, badges and leader boards, it is also about the use of game-design techniques (Werbach \& Hunter, 2012).

Depending on their level of abstraction, game elements - the tools to create gamification scenarios - can be subdivided into three non exhaustive categories. (1) Dynamics are the highest level of abstraction and stand for the big picture of a gamification system, yet they cannot be added directly (Werbach \& Hunter, 2012). Dynamics can be constraints, emotions, narrative, progression or relationships. (2) Mechanics are basic gamification processes that can be challenges, chance, competition, cooperation, feedback or rewards. (3) Components are specific forms of elements, which arise from the dynamics or mechanics. These components can be achievements, avatars, collections, levels, quests or virtual goods (Werbach \& Hunter, 2012). Levels (components), for example, give the player feedback (mechanics) and create a sense of progression (dynamics).

To show how gamification can address staff motivation (in logistics), exemplary gamification elements will be considered more precisely in regard to the psychological context in which they function. Therefore, the above-mentioned perspectives will be used.

1. From a trait perspective, the need for self-fulfilment, recognition and affiliation can be seen as stable sources of motivation. By creating a strong attachment to a meaningful and awe-inspiring story that personally involves the player, the need for self-fulfilment can be met. This so-called epic meaning (cf. McGonigal, 2011) gives the player the feeling of doing something meaningful and important. Recognition and affiliation can be illustrated by badges. They work as virtual status symbols and function as group identification by communicating shared experiences and activities (Antin \& Churchill, 2011).

2. A quite common principle in gamification is reinforcement and punishment. In the sense of a behaviourist learning perspective, this can be called operant conditioning. Leveling up or loosing a virtual life can be examples of that. Here, the role of immediate reinforcing feedback is an important element, which should be considered for the effective design of motivating gamification scenarios.

3. From a cognitive perspective, motivation depends on means-ends analysis. Clear goals and a high value of consequences can facilitate motivation. By providing a goal in form of a quest, the players experience challenges with clear objectives and rewards. Within these quests, the player has to use problemsolving activities to choose between potential solutions or alternative paths 
(Hense \& Mandl, 2012). Additionally, the value of consequences can be supported by badges because they show other users what a player has performed and what the player is capable of (Antin \& Churchill, 2011).

4. Being in control and master a situation fosters the players' self-efficacy, which relates to the feeling of competence (Hense \& Mandl, 2012). Offering different opportunities and choices can be a way to provide autonomy. Relatedness refers to options for cooperation, as well as possibilities to share achievements and to give the player the feeling of being part of a community (cf. Antin \& Churchill, 2011). These psychological needs for competence, autonomy, and relatedness are crucial for intrinsic motivation, as a self-determination perspective suggests.

5. Gamification scenarios should offer many choices. Regarding the story and the resultant quests, in particular, players should have the opportunity to hit their own preferences. This can foster intrinsic motivation and facilitate flow. From a perspective of interest, this relation between the player and the context is crucial for motivation.

To foster staff motivation in logistics, it is important to look trough the lens of more than one of these perspectives when designing a gamification system. The next section introduces the interdisciplinary GameLog project, which aims to implement the above-mentioned concepts in logistics.

\section{The GameLog project}

The GameLog research project as an interdisciplinary approach combines perceptions and problem-solving methods from the fields of Logistics, Motivational Psychology and Gaming Science. It is operated by the Institute for Material Handling Material Flow Logistics of the Technische Universität München and the chair for Empirical Pedagogy and Educational Psychology of the Ludwig-MaximiliansUniversität München. The project covers both theoretical basic research and applied science. Acquired insights will be implemented in a test environment for functional testing and feasibility studies and close cooperation with the participating industrial companies will be maintained to obtain an application-oriented and viable result.

The project pursues two major objectives, one applied and one research objective. On the one hand, the feasibility of a value-adding integration of professional gaming elements into intralogistical processes should be evaluated. On the other hand, a gamification system for order picking (see Fig.1) should be implemented in a laboratory environment and examined in trials with test subjects to see how it influences a user's motivation. The GameLog project is divided into 9 major work packages: (1) Analysis of current approaches to staff motivation in logistics; (2) Feasibility study of gamification elements in order picking processes; (3) Devel- 
opment and evaluation of gaming concepts; (4) Development of story, mechanics and reward structure; (5) Selection of soft- and hardware; (6) Development and implementation of a prototype test environment; (7) Evaluation of the test environment; (8) Validation and improvement of the test environment; (9) Documentation and Transfer of the project results;

After assessing the test environment, we expect to be able to implement the gamification system in other order picking processes of our project partners as well.

\section{Outlook}

Gamification has quickly become a popular trend in many contexts recently. While examples of uses for a multitude of goals in diverse settings are abundant, fostering staff motivation in logistics is still an innovative application. We expect that our project will bring forth results on several levels.

For the practice of intralogistics, we expect to develop readily applicable solutions for alleviating motivational problems in order picking. It is anticipated that this can contribute to an increased productivity and reduced costs for breaking in new staff.

On a research level, we intend to gain detailed insights into the general applicability of gamification approaches in labour contexts. In doing so, we consider gamification not as a monolithic construct. Instead, our approach is to differentiate between specific gamification elements and analyze their respective potentials and limits within a given practical labour setting. Beyond the general question 'will it work?', we aim to address the question "what gamification elements work by which motivational mechanisms in a given context?" on a conceptual an empirical level.

On a general note, we share the expectation that gamification has an inherent potential for positively impacting learning and behaviour. However, as noted by others (Deterding, 2011), the games themselves are not the solution, but well designed games. This emphasizes the need for a well planned approach grounded in gamification and psychological theory, if one seeks to fully realize the potentials of gamification for motivation.

\section{Acknowledgements}

Work on this paper was partly funded by the German Federal Ministry of Economics and Technology via the German Federal Logistics Association (grant no. $456 \mathrm{ZN})$ 


\section{References}

Antin, J., \& Churchill, E. F. (2011). Badges in Social Media: A Social Psychological Perspective. Proceedings of the Conference of Human-computer Interaction. Vancouver: ACM.

Arnold, D. (ed.) (2006). Intralogistik. Potentiale, Perspektiven, Prognosen [Intralogistics. Potentials, perspectives, prognoses]. Berlin: Springer.

Bundesverband Materialwirtschaft, Einkauf und Logistik (2008). Best Practice in Einkauf und Logistik [Best Practice in purchasing and logistics] (2nd ed.). Wiesbaden: Gabler.

Christopher, M. (2003). New directions in logistics. In D. Waters (ed.), Global logistics and distribution planning ( $4^{\text {th }}$ ed.), pp. 22-32. London: Kogan Page.

Coffey, D. (1999). Zero in on Picking. Logistics \& Transport Focus, 1(4), 22-25.

Deterding, S., Dixon, D., Khaled, R., Nacke, L. (2011). From Game Design Elements to Gamefulness: Defining "Gamification". Proceedings of the $15^{\text {th }}$ International Academic MindTrek Conference: Envisioning Future Media Environments. Tampere: ACM.

Hense, J. \& Mandl, H. (2012). Learning in or with games? Quality criteria for digital learning games from the perspectives of learning, emotion, and motivation theory. In D.G. Sampson, J.M. Spector, D. Ifenthaler \& P. Isaias(eds.), Proceedings of the IADIS International Conference on Cognition and Exploratory Learning in the Digital Age (pp. 19-26). Madrid: IADIS.

Jünemann, R. \& Schmidt, T. (2000). Materialflußsysteme - Systemtechnische Grundlagen [Material flow systems - Basics of system technology]. Berlin: Springer.

Kapp, K. M. (2012). The Gamification of learning and instruction. San Francisco: Pfeiffer.

Krapp, A. (1993). Die Psychologie der Lernmotivation [The psychology of learning motivation]. Zeitschrift für Pädagogik [Journal of education], 39 (2), 187-206.

Link, I., Müller-Dauppert, B. \& Jung, K. (2012). Motivationsstudie 2012: Mitarbeitermotivation in der Logistik [Motivation study 2012: Staff motivation in logistics]. Franfurt a. M.: Miebach Consulting.

McGonigal, J. (2011). Reality is broken: Why games make us better and how they can change the world. New York: The Penguin Press.

Pfohl, H.-C. (2004a). Logistikmanagement - Konzeption und Funktionen [Logistics management - Concept and functions]. Berlin: Springer.

Pfohl, H.-C. (Hrsg.) (2004b). Personalführung in der Logistik - Innovative Ansätze und praktische Lösungen [Personnel management in logistics. Innovative approaches and practical solutions]. Hamburg: Deutscher Verkehrs-Verlag.

Pulverich, M. \& Schietinger, J. (Hrsg.) (2009). Handbuch Kommissionierung - Effizient picken und packen [Handbook order picking - Efficient picking and packaging]. München: Heinrich Vogel.

Ryan, R. M. \& Deci, E. L. (2000). Intrinsic and extrinsic motivation: Classic definitions and new directions. Contemporary Educational Psychology, 25, 54-76.

Schunk, D. H., Pintrich, P. R. \& Meece, J. L. (2007). Motivation in education. Theory, research, and applications. Upper Saddle River, NJ: Prentice Hall.

ten Hompel, M., Sadowsky, V. \& Beck, M. (2011). Kommissionierung: Materialflusssysteme 2 Planung und Berechnung der Kommissionierung in der Logistik [Order picking: Material flow systems 2 - Planning and calculation of order picking in logistics]. Berlin: Springer.

Wagner, U. (1995). Entgeltdifferenzierung in logistischen Bereichen [Differentiation of wages in logistics]. Wiesbaden: Deutscher Universitätsverlag.

Werbach, K., \& Hunter, D. (2012). For the Win: How Game Thinking Can Revolutionize Your Business. Philadelphia: Wharton Digital Press.

Zaunmüller, H. (2005). Anreizsysteme für das Wissensmanagement in KMU [Incentive systems for knowledge management in SMEs]. Wiesbaden: Deutscher Universitätsverlag. 